\title{
Comparative effectiveness of lumbar stabilization, dynamic strengthening, and Pilates on chronic low back pain: randomized clinical trial
}

\author{
Esha A. Bhadauria*, Peeyoosha Gurudut \\ Department of Orthopaedics Physiotherapy, KLE University's Institute of Physiotherapy, Belagavi, India
}

The aim of the present study was to compare three different forms of exercises namely lumbar stabilization, dynamic strengthening, and $\mathrm{Pi}$ lates on chronic low back pain (LBP) in terms of pain, range of motion, core strength and function. In this study, 44 subjects suffering from nonspecific LBP for more than 3 months were randomly allocated into the lumbar stabilization group, the dynamic strengthening group, and the Pilates group. Ten sessions of exercises for 3 weeks were prescribed along with interferential current and hot moist pack. Pain was assessed by visual analog scale, functional affection by modified Oswestry Disability Questionnaire, range of motion by assessing lumbar flexion and extension by modified Schober test and core strength was assessed by pressure biofeedback on day 1 and day 10 of the treatment. There was reduction of pain, improvement in range of motion, functional ability and core strength in all the 3 exercise groups. The improvement was significantly greater in the lumbar stabilization group for all the outcome measures, when compared the posttreatment after 10th session. Pairwise comparison showed that there was greater reduction of disability in the Pilates group than the dynamic strengthening group. It was concluded that the lumbar stabilization is more superior compared to the dynamic strengthening and Pilates in chronic nonspecific LBP. However, longterm benefits need to be assessed and compared with prospective follow-up studies.

Keywords: Chronic low back pain, Lumbar stabilization, Dynamic strengthening, Pilates

\section{INTRODUCTION}

Low back pain (LBP) is an economic burden to society, leading to functional disability resulting in loss of number of days at work. Literature review state that $75 \%$ or more patients with low back become temporarily disabled and around $5 \%$ people suffer from permanent disability (Frymoyer and Cats-Baril, 1991). The lifetime prevalence of LBP is reported to be as high as $84 \%$, and the prevalence of chronic LBP is about 23\% (Balagué et al., 2012).

The prevalence of LBP in Indian population has been found to range from $6.2 \%$ to $92 \%$ and found to increase with age and to be more common among females (Bindra et al., 2015). Low socioeconomic status, poor education, previous history of LBP, physical factors such as lifting heavy loads, repetitive job, prolonged static posture and awkward posture, psychosocial factors such as anxiety, depression, job dissatisfaction, lack of job control and mental stress, working hours and obesity have been found to be associated with LBP (Biering-Sørensen,1983).

LBP is defined as pain which starts below the scapulae and above the cleft of the buttocks, with or without radiation to the lower extremities, including nerve root pain or sciatica (Hayden et al., 2005).

Based on the etiology, LBP is classified as specific LBP and nonspecific LBP. Nonspecific LBP is defined as LBP not attributed to specific pathology (e.g., infection, tumor, osteoporosis, arthritis, fracture, Cauda equina syndrome, etc.). It is thought that in some cases the cause may be a sprain (an overstretch) of a ligament or muscle or minor problem with a disc, facet or minor problems in
${ }^{*}$ Corresponding author: Esha A. Bhadauria (D) https://orcid.org/0000-0003-2542-8022 Department of Orthopaedics Physiotherapy, KLE University's Institute of Physiotherapy, Belagavi, Karnataka, Belagavi, 590010, India

Tel: +91-832-231-6501, Fax: +91-831-249-3777, E-mail: sunshineesha123@gmail.com Received: April 18, 2017 / Accepted: July 28, 2017
This is an Open Access article distributed under the terms of the Creative Commons Attribution Non-Commercial License (http://creativecommons.org/licenses/by-nc/4.0/) which permits unrestricted non-commercial use, distribution, and reproduction in any medium, provided the original work is properly cited. 
the structures and tissues of the lower back that result in pain (Koes et al., 2006). LBP is also categorized in three subtypes based on duration of symptoms as: acute (lasting for few weeks), subacute (6-12 weeks), and chronic (more than 12 weeks) LBP (Krismer et al., 2007). Chronic pain is represented by a protective adaptive muscle response in which agonists and antagonists decrease and increase in tone respectively (Graven-Nielsen et al., 1997).

The management of LBP comprises with range of different interventional strategies, including drug therapy and nonmedical interventions. Nonsteroidal anti-inflammatory drugs may be of short-term benefit and are included in medical management. Physical therapy includes exercises and pain relieving modalities (Burton et al., 2006). Short wave diathermy, interferential currents and transcutaneous electrical nerve stimulation have been known to reduce muscle spasm and blocking pain (Deyo et al., 1990). There are various forms of exercise that can be prescribed based on different schools of thought. This includes intensive dynamic back extensor exercises (Manniche et al., 1991), motor control exercises (Macedo et al., 2009), yoga (Sherman et al., 2005), aerobic exercises (Sculco et al., 2001).

Lumbar stabilization exercises are aimed at improving the neuromuscular control, strength, and endurance of the muscles that are central to maintaining the dynamic spinal and trunk stability. The effect of lumbar stabilization exercise have been studied in subjects with recurrent LBP (Koumantakis et al., 2005), pelvic pain (Ferreira et al., 2006) and LBP with leg pain (Saal and Saal, 1989).

Dynamic strengthening exercises can strengthen the spinal column and supporting structures (Gladwell et al., 2006). An electromyography study to compare recruitment of rectus abdominis and erector spinae muscle during dynamic strengthening exercise revealed higher muscle activity in these muscles (Comfort et al., 2011).

Pilates focuses on maintaining a 'neutral spine,' pelvic and spinal stability, along with activation of transverse abdominals and pelvic floor muscles in combination with controlled breathing (Nadler et al., 2002). Pilates based therapeutic approach has been studied previously in subjects with chronic LBP and has proved to reduce pain and lower disability rate (Rydeard et al., 2006).

However, lumbar stabilization exercise, dynamic strengthening exercise, and Pilates exercise have not been compared with each other to determine which among these three exercises is more effective to reduce chronic nonspecific LBP. Hence, the present study was done with an objective to compare the short-term effect of lumbar stabilization, dynamic strengthening, and Pilates and find a better approach in clinical practice.

\section{MATERIALS AND METHODS}

\section{Study design}

This study was a single (assessor) blinded randomized clinical with a sample of convenience. The research setting was an outpatient department of a tertiary health care hospital located in Belgaum city of Karnataka, India. The study was conducted from March 2016 to February 2017. Ethical clearance was obtained from Institutional Ethical Review Committee (No. KIPT/460/16). All participants gave written informed consent prior to commencement of the study. Participants' rights were protected throughout the trial.

\section{Participants}

Consecutive presentations of people with a referral for LBP treatment to the physiotherapy department were screened. Participants who were clinically diagnosed with chronic LBP were recruited and further assessed for eligibility. The sample size was determined by preliminary power analysis to avoid error $5 \%$ a error and $95 \%$ power of the text. Sample size of 12 subjects in each group was obtained. The sample size was increased to account for possible dropouts. Forty-four subjects were assessed and randomly allocated in three groups by envelop method (Fig. 1).

The inclusion criteria were: (a) all male and female adults between age group of 20-60 years, (b) subjects with nonspecific back pain $>3$ months, and (c) subjects willing to participate in the study.

The subjects excluded were: (a) subjects with specific back pain (fracture, osteoporosis or degenerative changes, prolapse intervertebral disc, bone disorders, arthritis, tumour), (b) subjects with neurological involvement (radiculopathy, myelopathy), (c) subjects with previous spinal surgery, (d) subjects with spinal infections, and (e) subjects with severe psychiatric disorder.

\section{Intervention}

The study participants were given brief idea about the natives of the study and intervention. Hot moist pack (HMP) and interferential current were given as a part of conventional treatment for all the participants. The total therapy lasted for $60 \mathrm{~min}$. The assessor was blinded to the intervention.

\section{Procedure for assessment}

For the visual analogue scale (VAS), the subject was asked to point out intensity of pain on a 0 - to $10-\mathrm{cm}$ scale (Zanoli et al., 2001). It is a valid, reliable, and precise method of recording pain 


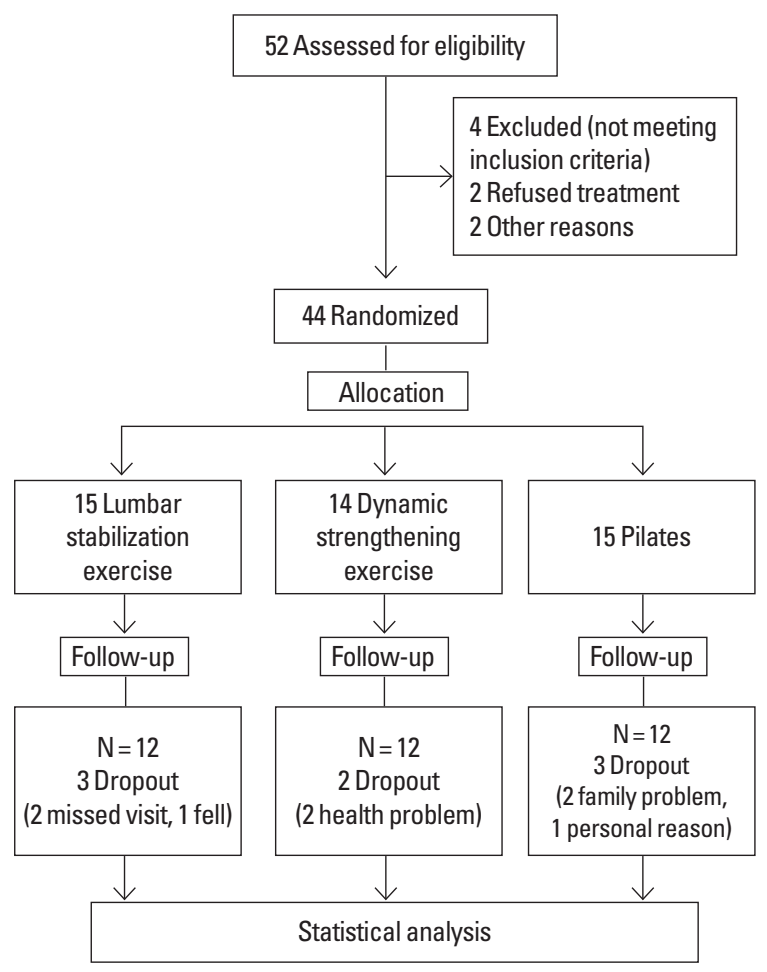

Fig. 1. Flow chart diagram.

(Carlsson, 1983). A well validated, self-reported questionnaire designed for low back containing 10 sections was used to assess the level of disability. Modified Oswestry Disability Questionnaire (MODQ) was used for this purpose (Fritz and Irrgang, 2001).

Lumbar range of motion was assessed using modified Schober method. This was assessed in standing position, the intersection of dimples of venus on lower back was marked with marker as reference line, a line was drawn $10 \mathrm{~cm}$ above and $5 \mathrm{~cm}$ below the reference line, subject was then asked to bend forward, backward. Lateral flexion on both the sides was asked to perform on command and measurement was taken using measuring tape. The differences between these points are outcome measures. The validity of this method was proved against radiographs (Tousignant et al., 2005).

Core muscle strength was measured using Pressure Biofeedback (Chattanooga Group Inc., Hixson, TN, USA). The device consists of three chamber pressure cells which were placed under the lumbar spine in crook lying and inflated to a baseline of $40 \mathrm{mmHg}$. The subjects were told to increase the pressure by $10 \mathrm{mmHg}$ using the drawing-in maneuver on the verbal instruction, "Start," and to maintain the state for $5 \mathrm{sec}$. The measuring range was 0 - to 20-mmHg analog pressure with accuracy of $+/-3 \mathrm{MHz}$ pressure (Storheim et al., 2002).

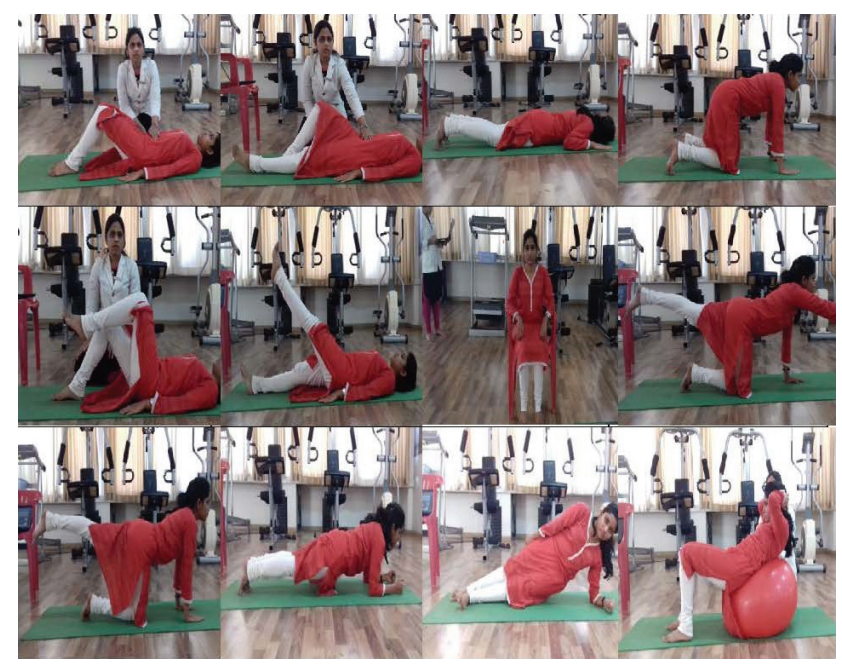

Fig. 2. Stabilization exercise.

\section{Intervention}

Patient was made to lie in prone or side lying position as per the comfort of the patient. HMP (India Medico Instruments Co., New Delhi, India) was applied for the duration of 15 min on low back region to reduce spasm followed by interferential current (IFT) for $20 \mathrm{~min}$. Two-channel electrodes $(5 \mathrm{~cm} \times 10 \mathrm{~cm})$ were positioned to close pain circuit being placed in the lumbar spine on the central pain point. Carrier frequency is $4,000 \mathrm{~Hz}$, with modulated frequency amplitude (MFA) of $20 \mathrm{~Hz}, \Delta$ MFA of $10 \mathrm{~Hz}$ and intensity was increased as per the tolerance of the subject (Zambito et al., 2006). All subjects in both groups performed warm up stretching exercises for $10 \mathrm{~min}$ before the main exercises and cool down exercises for $5 \mathrm{~min}$ after each session.

\section{Lumbar stabilization exercise group}

There were 16 lumbar stabilization exercises prescribed once, and were performed consecutively and in order for total 10 sessions. Subjects practiced "hollowing" with a therapist providing verbal instruction and tactile feedback (Fig. 2).

\section{Pilates group}

In the first session, the participants of both groups were trained to activate the powerhouse, which represents the isometric contraction. This included finding neutral spine, breathing practice, engaging pelvic floor and the transverse (Fig. 3).

\section{Dynamic strengthening exercise group}

Lumbar dynamic strengthening exercises consisted of 14 exercises, which activated the extensor (erector spinae) and flexor (rec- 
tus abdominis) muscle groups. For all exercises in both groups, the final static positions were held for $10 \mathrm{sec}$, and each exercise was performed for 10 repetitions. There was a pause of $3 \mathrm{sec}$ between repetitions and a 60-sec rest between each exercise. Exercise intensity (holding time and number of repetition) were increased gradually, based on the tolerance of each patient (Fig. 4).

\section{Statistical analysis}

After completion of the study, data collected was entered into excel spread sheet, tabulated and subjected to statistical analysis. Statistical analysis for the present study was done manually as well as using IBM SPSS Statistics ver. 20.0 (IBM Co., Armonk, NY, USA). Applied paired $t$-test was calculated by one-way analysis of variance (ANOVA) and $P<0.005$ was considered significant. Probability value less than 0.05 was considered statistically significant. The pair wise comparison of groups by Tukey multiple post boc procedures.

Nominal data from subject's demographic data i.e., age, body mass index (BMI), duration of symptoms was calculated by oneway ANOVA (Table 1). The normative values of outcome measure like VAS, MODQ, lumbar flexion and extension, core strength

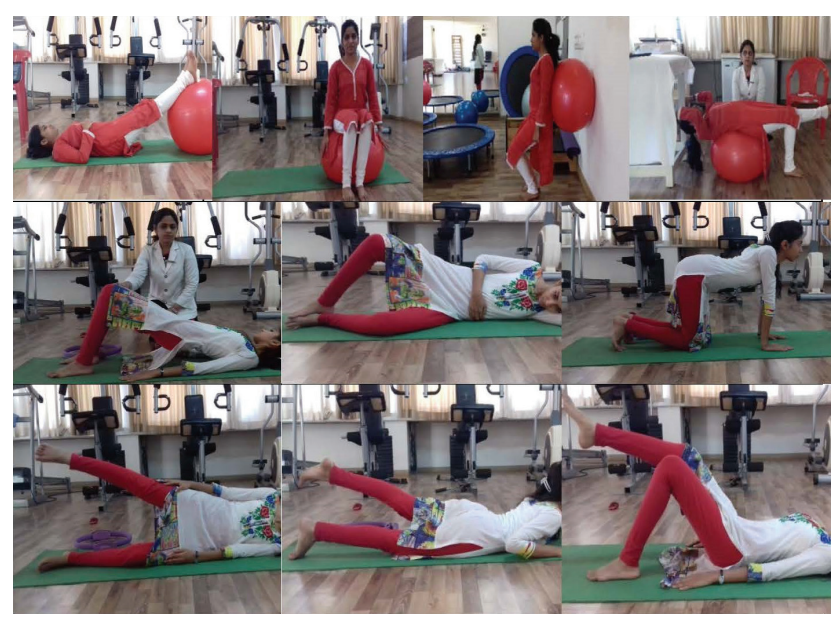

Fig. 3. Pilates. were analyzed using Kolmogorov-Smirnov test. Since all the pretest and posttest scores of different variables in study groups follow normal distribution therefore parametric test is applied.

\section{RESULTS}

At the end of ten sessions of intervention, 44 subjects who met the inclusion criteria participated in this interventional study. Twelve of the subjects (age, $32.75 \pm 11.73$ years; BMI, 21.78 \pm $2.87 \mathrm{~kg} / \mathrm{m}^{2}$ ) were in the lumbar stabilization group. Twelve of the subjects (age, $36.67 \pm 10.74$ years; BMI, $24.71 \pm 4.55 \mathrm{~kg} / \mathrm{m}^{2}$ ) were in the dynamic strengthening group. Twelve of the subjects (age,

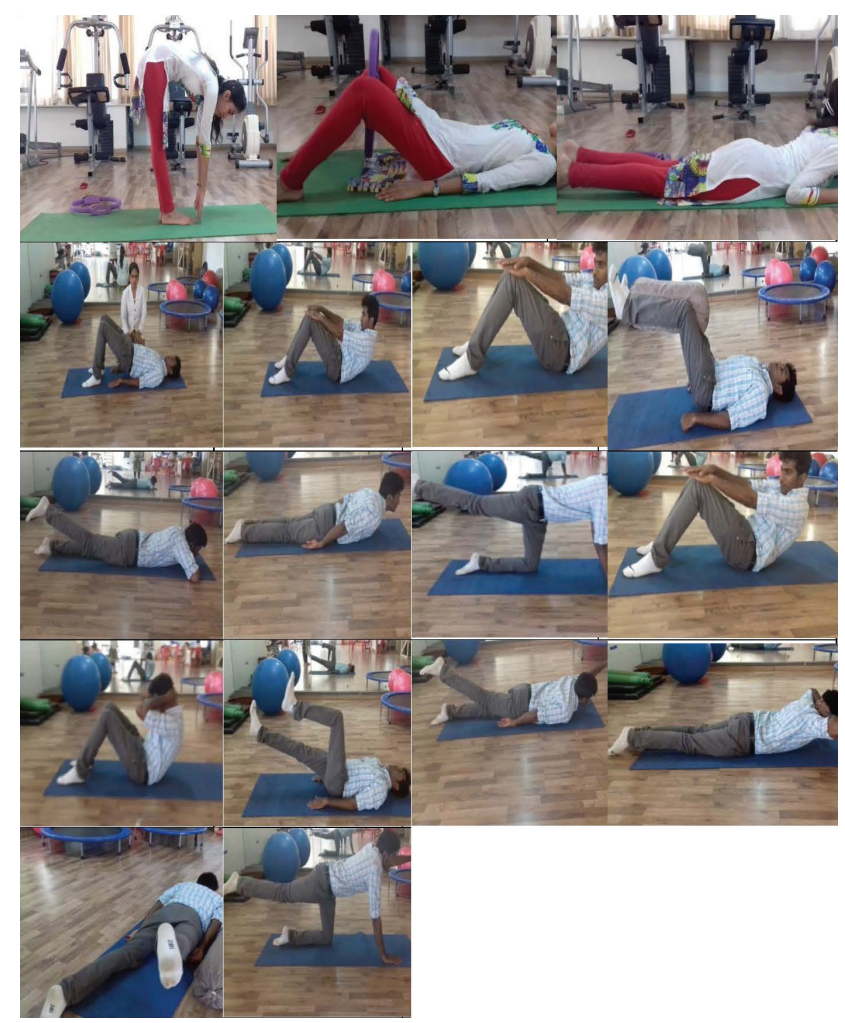

Fig. 4. Strengthening exercise.

Table 1. Demographic data of all the study groups

\begin{tabular}{|c|c|c|c|c|}
\hline \multirow{2}{*}{ Characteristic } & \multicolumn{3}{|c|}{ Group } & \multirow{2}{*}{$P$-value } \\
\hline & Lumbar stabilization & Dynamic strengthening & Pilates & \\
\hline Age (yr) & $32.75 \pm 11.73$ & $36.67 \pm 10.74$ & $35.33 \pm 12.88$ & 0.7615 \\
\hline Sex, female:male (\%) & $50: 50$ & 41.6:58.33 & 8.3:91.6 & \\
\hline Body mass index $\left(\mathrm{kg} / \mathrm{m}^{2}\right)$ & $21.78 \pm 2.87$ & $24.71 \pm 4.55$ & $25.95 \pm 6.19$ & 0.1012 \\
\hline Duration of symptoms (yr) & $0.58 \pm 0.54$ & $0.31 \pm 0.42$ & $1.53 \pm 1.64$ & $0.0165^{*}$ \\
\hline
\end{tabular}

Values are presented as mean \pm standard deviation.

${ }^{*} P<0.05$. 
$35.33 \pm 12.88$ years; BMI, $25.95 \pm 6.19 \mathrm{~kg} / \mathrm{m}^{2}$ ) were in the Pilates group. The duration of symptoms in lumbar stabilization group was $0.58 \pm 0.54$ years, dynamic strengthening group $0.31 \pm 0.42$ and $1.53 \pm 1.64$ in the Pilates group. Duration of symptoms of LBP varied significantly with the Pilates group having longer duration of pain.

For lumbar stabilization group, score changes for VAS, MODQ, lumbar flexion and extension, and core strength were significant within the group. However when between group study was done and lumbar stabilization group was compared to other two groups, the pain was found to be significantly reduced in the lumbar stabilization group with $P$-value of 0.0001 compared to dynamic strengthening exercise. MODQ scores were found to be significantly reduced with $P$-value of 0.0001 when compared to the dynamic strengthening group and when compared to the Pilates group, $P$-value was reduced significantly 0.0001 (Table 2 ). When lumbar flexion was assessed the $P$-value of stabilization group was significantly improved at 0.001 when compared to dynamic strengthening and $P$-value was significantly improved at 0.0001 when compared to the Pilates group. Lumbar extension range was found to be significantly improved with $P$-value of 0.0001 when compared to the Pilates group. Core strength was found to be significantly better with $P$-value of 0.0001 when compared to the Pilates group (Table 3).

The dynamic strengthening, score changes for VAS, MODQ, lumbar flexion and extension, and core strength were more significant within the group. However when between the group analysis was done and dynamic strengthening group was compared to other two groups, the pain did not significantly reduce in dynamic strengthening compared to the Pilates and stabilization groups. When disability was assessed, the MODQ score was significantly reduced with $P$-value of 0.0001 compared to the Pilates group. When lumbar flexion was assessed the $P$-value of dynamic strengthening group was not significant when compared to the Pilates and lumbar stabilization groups. Lumbar extension range did not significantly improve when compared to the Pilates and the stabilization groups. Core strength did not significantly improve in the dynamic strengthening group when compared to the Pilates and the stabilization groups.

In the Pilates group, VAS, MODQ, lumbar flexion and extension, and core strength were significant within the group. However when between the group analysis was done, it was seen that the pain did not significantly reduce in Pilates group when compared to dynamic strengthening and lumbar stabilization groups. The MODQ score was reduced in the Pilates group when to dy-
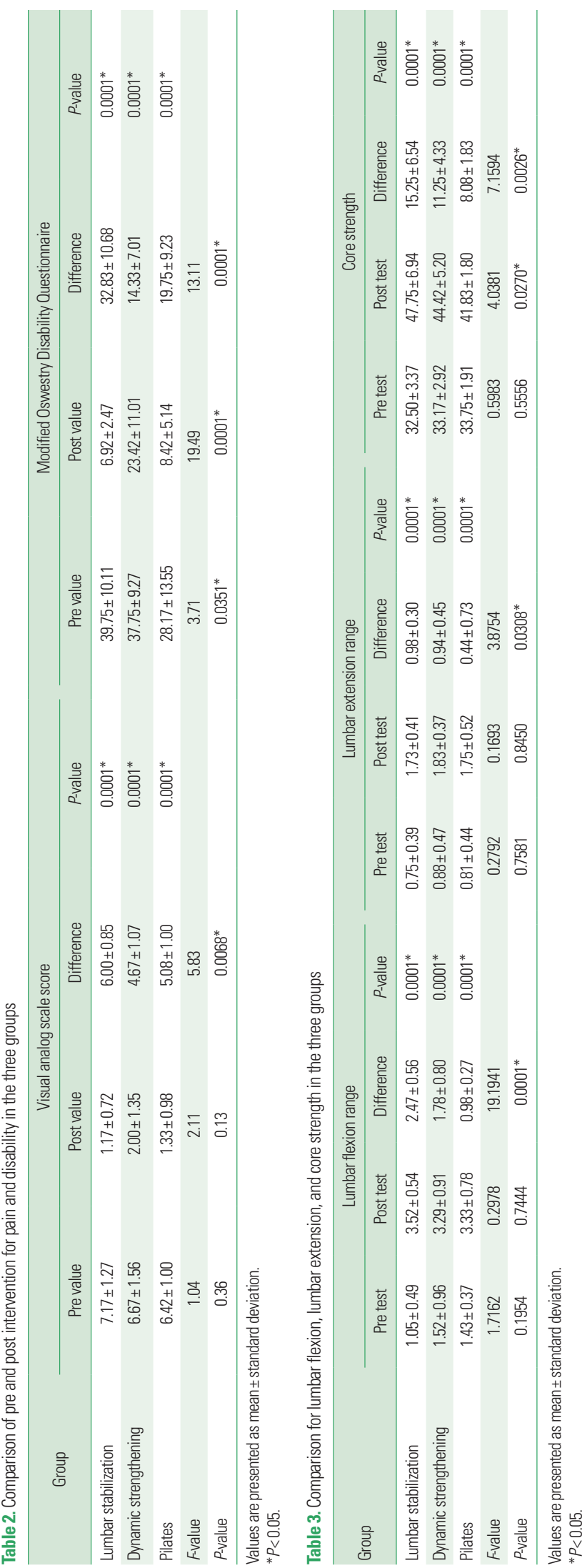
namic strengthening group but was not found to be significant. When lumbar flexion was assessed the $P$-value of the Pilates group was not significant when compared to the dynamic strengthening and the lumbar stabilization groups. Lumbar extension range did not significantly improve when compared to the dynamic strengthening and the lumbar stabilization groups. Core strength did not significantly improve in the Pilates group when compared to the dynamic strengthening and the lumbar stabilization groups.

\section{DISCUSSION}

In the present study it was found that although all the three forms of exercises proved to be effective when pre-post intervention comparison was made on day 1 and day 10 of treatment session, the inter group comparison proved lumbar stabilization exercise to be more superior form of exercise when compared to the dynamic strengthening and the Pilates groups. Dynamic strengthening group showed better results than the Pilates group except in MODQ scores where Pilates showed reduction in disability compared to the dynamic strengthening group.

In the present study, the homogeneity of the subjects was maintained as all the demographic data was matched except duration of pain symptoms which was found to be more in Pilates group. Subjects with back pain were maximal in the age group of 29-50 years which shows that chronic nonspecific back pain occurs mostly in working age group due to occupation, daily activity and stress (Bindra et al., 2015). Gender distribution in the present study showed that large number of females complaint back pain as seen in previous studies. The reason might be ascribed to that lumbar lordosis is more prominent in females (Han et al., 1997). Studies also quote that compared with persons of normal BMI, overweight/obese people had an increased prevalence of LBP (Shiri et al., 2010). This relation has been proved in our study.

The standard conventional treatment for nonspecific LBP include HMP (Nadler et al., 2002) interferential current (Poitras and Brosseau, 2008) and exercises (Hayden et al., 2005). Keeping this into account HMP and interferential current was given. Moist hot pack was used to reduce pain and superficial muscle spasm, and to improve tissue extensibility. Interferential current was given to reduce pain as it works on pain gate theory and neurotransmitter depletion.

Stabilization exercise was found to be superior among all forms of exercise in the present study. This could be explained with following possible reasons. Firstly, the stabilization exercise uses drawing-in maneuver which helps in coactivating the transversus abdominis and multifidus muscles than other exercises which concentrate on strengthening the surrounding muscle. The drawing-in maneuver develops the pattern of setting the deep abdominal and multifidus in feedforward pattern and helps to maintain the holding capacity and in coordination with the global muscles. Secondly, tactile facilitation along with verbal cues were also given to explain the muscles encircling the trunk which acts as feedback and third reason may be that all the 16 exercises were performed consecutively one after the other without any repetitions and no rest period was given to maintain the posture this helps to sustain the cocontraction of the muscle while performing the exercise.

The postures used in the exercises given to lumbar stabilization group were specific to the particular muscle so as the muscles were activated. Primary training in hook lying $\left(70^{\circ}-90^{\circ}\right.$ of knee flexion) is slowly progressed to prone lying to sitting followed by functional activities. Extremity motions were added and were used to stimulate muscle endurance and strengthen the trunk muscles. In prone position the load to lumbar spine increases on extremity loading hence extension exercise were initiated in quadruped position to maintain lumbar in neutral position and for patient to learn control. The quadratus lumborum acts as stabilizer in frontal and transverse plane. Hence side propping position was maintained to activate quadratus lumborum and external oblique. The same recruitment of muscle can be taught to patient by self-palpation and sitting and rocking on Bobath ball. For this reason, stabilization exercise can be included in home program. Lumbar stabilization exercise also strengthens the lumbar extensors thereby improving functional ability and lumbar range of motion.

Generally, Oswestry Disability Questionnaire score less than 20 indicates functional disability and is not regarded as significant in daily life. In the previous study stabilization exercise reported significant improvement in function which is in accordance to the present study. MODQ score showed improvement after the stabilization exercise. In one of the previous study, the core strength of various muscles acting during stabilization exercise was assessed by pressure biofeedback and electromyogram (EMG) studies. Results demonstrated significantly increased activity of the gluteus medius and internal oblique activity were increased significantly, and the quadratus lumborum activity was decreased significantly, causing reduced lateral pelvic tilt in a side lying position (de Paula Lima et al., 2011). The present study also used pressure biofeedback for assessing the core strength, which showed significant improvement in muscle recruitment after the lumbar stabilization exercise.

The Pilates is based on the use of functional exercises for im- 
proving muscular strength and endurance and train these muscles. The Pilates, which focused on rehabilitation, recruit deep stabilizer muscles (i.e., transverses abdominis, internal and external abdominal obliqus, and multifidus muscles) at a submaximal effort, while disassociating the extremities from the trunk and pelvis, so that the deep stabilizers work efficiently to maintain control. This suggests that lumbar stabilization exercises are as good as Pilates. However, in our study the Pilates did not improve functionality and pain as much as the lumbar stabilization exercise group.

The Pilates also showed better results in pain reduction and disability and range of motion. Pilates improved absolute core strength and moreover encouraged proper activation patterns of core musculature. The mat program in this group of exercises trained core stabilization, specific muscle activation strategies to stabilize the lumbar-pelvic region with neuromuscular control and spinal stability. However, it showed minimal results. The reason might be that the Pilates group intervention lasted for short duration when compared to other studies. Pilates program was found to be effective after 6-week protocol. The subjects in the Pilates group had more duration of symptoms when compared to lumbar stabilization and dynamic strengthening exercise groups.

Pilates exercise for the improvement of LBP was studied in previous randomized controlled trial where the Pilates group undertook a 6-week program. These data suggest that Pilates improved nonspecific chronic LBP in an active population compared to no intervention. Additionally, Pilates improved general health, pain level, sports functioning, flexibility, and proprioception in individuals with chronic LBP (Gladwell et al., 2006).

A systematic review was carried out assessing the effects of the Pilates method on chronic LBP patients. This systematic review did not find evidence that Pilates was superior to lumbar stabilization exercises for pain relief or functional improvement but as good as stabilization exercise (Pereira et al., 2012). This could be because the long-term effects were not studied.

Dynamic strengthening exercises showed improvement in all outcomes whereas pain and disability scores did not show major reduction when compared to lumbar stabilization and Pilates exercises. Dynamic strengthening exercise is the one with spinal movement demonstrating effective core and global stabilization technique and endurance in stabilizing musculature. The dynamic strengthening exercises involve only mobility and strength of spinal muscles. In dynamic strengthening exercises, due to the load imposed on the spine, patients' low back symptoms may increase which might affect minimal pain reduction and improvement in daily activities.
Various muscles work during dynamic strengthening exercises. EMG studies suggest curls up which recruits the rectus abdominis, with low activity in obliques, transversus abdominis and psoas, sit ups with straight leg and bent knee show high rectus and external oblique activity, high psoas activity and high low back compression, heel press sit ups increase psoas activity, hanging leg raises show high external oblique and high spinal compression, supine single leg lifts show deep stabilizing muscle activation. Supermen exercises are progressed by having the patient lift both upper and lower extremities simultaneously, greater resistance can be provided by abducting the shoulders to $90^{\circ}$ or elevating $180^{\circ}$. Strengthening the extensor muscles and an improved extensor/ flexor ratio has found to be important in reducing symptoms in chronic LBP patients. A study demonstrated that lumbar training is necessary to develop paravertebral muscle strength and bulk.

A study was conducted to compare the efficacy of stabilization and strengthening exercises on relief of chronic LBP symptoms (Moon et al., 2013). Both treatments were effective in relieving pain and in decreasing functional impairment, but only the stabilization treatment improved tranversus abdominus muscle activation. Better results of the stabilization group may be explained by the fact that this technique addresses two muscles primarily affected by LBP i.e., lumbar multifidus and tranversus abdominus. But, in the dynamic strengthening group, the exercises were focused on the rectus abdominis, abdominus obliquus internus, abdominus obliquus externus, and erector spinae. Also, the program lasted for 6 weeks, and 30-min sessions were given twice a week. However, in the present study the treatment program was given only 10 sessions.

There was no long-term follow-up as there would be more chances of dropouts, Time duration for exercises is 10 sessions only in order to avoid loss of subjects in follow-up. Sophisticated procedures like EMG studies or ultrasound measurements were not monitored to study the strength and activation of deep muscles due to unavailability of the equipment. Longer follow-up period should be considered and incorporate EMG studies or ultrasound imaging to monitor muscle recruitment after exercise to confirm the increase in muscle activation.

On the basis of the present study it can be concluded that lumbar stabilization exercise, dynamic strengthening exercise and Pilates are beneficial in the treatment of chronic nonspecific LBP for reduction of pain, improvement in functional ability, increase range of motion and improve core strength. However when compared, lumbar stabilization proved to be more effective form of exercise than Pilates and dynamic strengthening for chronic LBP. 


\section{CONFLICT OF INTEREST}

No potential conflict of interest relevant to this article was reported.

\section{REFERENCES}

Balagué F, Mannion AF, Pellisé F, Cedraschi C. Non-specific low back pain. Lancet 2012;379:482-491.

Biering-Sørensen F. A prospective study of low back pain in a general population. I. Occurrence, recurrence and aetiology. Scand J Rehabil Med 1983;15:71-79.

Bindra S, Sinha AK, Benjamin AI. Epidemiology of low back pain in Indian population: a review. Int J Appl Basic Med Res 2015;5:166-179.

Burton AK, Balagué F, Cardon G, Eriksen HR, Henrotin Y, Lahad A, Leclerc A, Müller G, van der Beek AJ; COST B13 Working Group on Guidelines for Prevention in Low Back Pain. Chapter 2. European guidelines for prevention in low back pain: November 2004. Eur Spine J 2006;15 Suppl 2:S136-168.

Carlsson AM. Assessment of chronic pain. I. Aspects of the reliability and validity of the visual analogue scale. Pain 1983;16:87-101.

Comfort P, Pearson SJ, Mather D. An electromyographical comparison of trunk muscle activity during isometric trunk and dynamic strengthening exercises. J Strength Cond Res 2011;25:149-154.

de Paula Lima PO, de Oliveira RR, Costa LO, Laurentino GE. Measurement properties of the pressure biofeedback unit in the evaluation of transversus abdominis muscle activity: a systematic review. Physiotherapy 2011;97:100-106.

Deyo RA, Walsh NE, Martin DC, Schoenfeld LS, Ramamurthy S. A controlled trial of transcutaneous electrical nerve stimulation (TENS) and exercise for chronic low back pain. N Engl J Med 1990;322:1627-1634.

Ferreira PH, Ferreira ML, Maher CG, Herbert RD, Refshauge K. Specific stabilisation exercise for spinal and pelvic pain: a systematic review. Aust J Physiother 2006;52:79-88

Fritz JM, Irrgang JJ. A comparison of a modified Oswestry Low Back Pain Disability Questionnaire and the Quebec Back Pain Disability Scale. Phys Ther 2001;81:776-788.

Frymoyer JW, Cats-Baril WL. An overview of the incidences and costs of low back pain. Orthop Clin North Am 1991;22:263-271.

Gladwell V, Head S, Haggar M, Beneke R. Does a program of Pilates improve chronic non-specific low back pain? J Sport Rehabil 2006;15:338350.

Graven-Nielsen T, Svensson P, Arendt-Nielsen L. Effects of experimental muscle pain on muscle activity and co-ordination during static and dynamic motor function. Electroencephalogr Clin Neurophysiol
1997:105:156-164.

Han TS, Schouten JS, Lean ME, Seidell JC. The prevalence of low back pain and associations with body fatness, fat distribution and height. Int J Obes Relat Metab Disord 1997;21:600-607.

Hayden JA, van Tulder MW, Malmivaara A, Koes BW. Exercise therapy for treatment of non-specific low back pain. Cochrane Database Syst Rev 2005;(3):CD000335.

Koes BW, van Tulder MW, Thomas S. Diagnosis and treatment of low back pain. BMJ 2006;332:1430-1434.

Koumantakis GA, Watson PJ, Oldham JA. Trunk muscle stabilization training plus general exercise versus general exercise only: randomized controlled trial of patients with recurrent low back pain. Phys Ther 2005;85:209-225.

Krismer M, van Tulder M; Low Back Pain Group of the Bone and Joint Health Strategies for Europe Project. Strategies for prevention and management of musculoskeletal conditions. Low back pain (non-specific). Best Pract Res Clin Rheumatol 2007;21:77-91.

Macedo LG, Maher CG, Latimer J, McAuley JH. Motor control exercise for persistent, nonspecific low back pain: a systematic review. Phys Ther 2009;89:9-25.

Manniche C, Lundberg E, Christensen I, Bentzen L, Hesselsøe G. Intensive dynamic back exercises for chronic low back pain: a clinical trial. Pain 1991;47:53-63.

Moon HJ, Choi KH, Kim DH, Kim HJ, Cho YK, Lee KH, Kim JH, Choi YJ. Effect of lumbar stabilization and dynamic lumbar strengthening exercises in patients with chronic low back pain. Ann Rehabil Med 2013;37:110-117.

Nadler SF, Steiner DJ, Erasala GN, Hengehold DA, Hinkle RT, Beth Goodale M, Abeln SB, Weingand KW. Continuous low-level heat wrap therapy provides more efficacy than Ibuprofen and acetaminophen for acute low back pain. Spine (Phila Pa 1976) 2002;27:1012-1017.

Pereira LM, Obara K, Dias JM, Menacho MO, Guariglia DA, Schiavoni D, Pereira HM, Cardoso JR. Comparing the Pilates method with no exercise or lumbar stabilization for pain and functionality in patients with chronic low back pain: systematic review and meta-analysis. Clin Rehabil 2012;26:10-20.

Poitras S, Brosseau L. Evidence-informed management of chronic low back pain with transcutaneous electrical nerve stimulation, interferential current, electrical muscle stimulation, ultrasound, and thermotherapy. Spine J 2008;8:226-233.

Rydeard R, Leger A, Smith D. Pilates-based therapeutic exercise: effect on subjects with nonspecific chronic low back pain and functional disability: a randomized controlled trial. J Orthop Sports Phys Ther 2006;36:472-484.

Saal JA, Saal JS. Nonoperative treatment of herniated lumbar interverte- 
bral disc with radiculopathy. An outcome study. Spine (Phila Pa 1976) 1989;14:431-437.

Sculco AD, Paup DC, Fernhall B, Sculco MJ. Effects of aerobic exercise on low back pain patients in treatment. Spine J 2001;1:95-101.

Sherman KJ, Cherkin DC, Erro J, Miglioretti DL, Deyo RA. Comparing yoga, exercise, and a self-care book for chronic low back pain: a randomized, controlled trial. Ann Intern Med 2005;143:849-856.

Shiri R, Karppinen J, Leino-Arjas P, Solovieva S, Viikari-Juntura E. The association between obesity and low back pain: a meta-analysis. Am J Epidemiol 2010;171:135-154.

Storheim K, Bø K, Pederstad O, Jahnsen R. Intra-tester reproducibility of pressure biofeedback in measurement of transversus abdominis func- tion. Physiother Res Int 2002;7:239-249.

Tousignant M, Poulin L, Marchand S, Viau A, Place C. The Modified-Modified Schober Test for range of motion assessment of lumbar flexion in patients with low back pain: a study of criterion validity, intra- and inter-rater reliability and minimum metrically detectable change. Disabil Rehabil 2005;27:553-559.

Zambito A, Bianchini D, Gatti D, Viapiana O, Rossini M, Adami S. Interferential and horizontal therapies in chronic low back pain: a randomized, double blind, clinical study. Clin Exp Rheumatol 2006;24:534-539.

Zanoli G, Strömqvist B, Jönsson B. Visual analog scales for interpretation of back and leg pain intensity in patients operated for degenerative lumbar spine disorders. Spine (Phila Pa 1976) 2001;26:2375-2380. 